\title{
THE IPL 60+ PROGRAM: A SINGULAR CASE OF SENIOR EDUCATION IN AN INTERGENERATIONAL CONTEXT
}

\author{
Luísa Pimentel ${ }^{24}$, Isabel Varregoso ${ }^{25}$, Susana Faria ${ }^{26}$, Ana Comprido ${ }^{27}$
}

\begin{abstract}
Aiming for the promotion of active aging, the IPL60+ Senior Education Program is designed for adults over 50 years old and is part of the Polytechnic Institute of Leiria Strategic Plan since 2008, allowing its enrolled members to attend Curricular Units from any of the IPL's graduation courses.

Therefore, the Program is conceived as an intergenerational senior education initiative. Its mission is to help change the aging paradigm through the stimulation and promotion of formative, educational and socio-cultural activities that involve the individuals in their own learning path and lifelong development, always in an intergenerational sociability context able to strengthen mutual learning processes. By enrolling in regular classes, senior students share school premises with the younger students, being able to benefit from all the IPL Campus' services and spaces including classrooms, as well as canteens, cafeterias and libraries.

In parallel, the IPL60+ Program has been striving to complement the academic component, diversifying the offer of intellectual and physically stimulating activities that are appropriate to this specific audience. Simultaneously, there is a constant appeal to personal intervention and initiative, valuing the students' cooperation in the organization of a series of their own initiatives, some with a clearly educational tone, others more recreational.
\end{abstract}

${ }^{24}$ School of Education and Social Sciences of Polytechnic Institute of Leiria (ESECS/IPL).

Email: luisa.pimentel@ipleiria.pt; Centre for Research and Studies in Sociology of University Institute of Lisbon (CIES/IUL).

25 Email: isabel.varregoso@ipleiria.pt; Research Centre for Studies in Human Motricity (CIMH/IPL).

26 Email: susana.sousa@ipleirira.pt; Research Centre for Identity(ies) and Diversity(ies) (CIID/IPL).

27 School of Education and Social Sciences of Polytechnic Institute of Leiria (ESECS/ IPL); Research Centre for Studies in Human Motricity (CIMH/IPL). 
Demand has been increasing substantially, expanding from 17 students enrolled in 2008 to 111 in the 2 nd semester of 2010/11.

Keywords: Active Aging; Intergenerational exchange; Senior education; Social participation.

\section{Introduction}

The IPL60+ is a Senior Education Program, developed by the IPL, which started in the second semester of 2007/2008. It aims to promote active aging, facilitating the integration of people over 50 years old in new social contexts and the construction of new relational networks. The Program promotes the sharing of knowledge and the acquisition of new knowledge and skills in an intergenerational context.

The Program has been well received by people who have retired recently, who maintain high levels of autonomy, willingness to participate socially and to complete their education. It is, in general, a population with medium or high levels of education, with qualified professional functions, demanding and with high expectations regarding the Program. They expect creative and exciting proposals and quality services.

The senior students have access to a diverse socio-cultural and educational offer. They also have access to all the services that IPL provides to the remaining students (canteens, libraries, multimedia resources, academic services, etc.).

Thus, in order to comply with the pillars supporting this Project - the promotion of intergenerational relationships and active aging - senior students can attend courses from graduate schools of IPL, joining in the normal context of class. Moreover, they can benefit from additional training, according to their interests and needs, in areas such as foreign languages and information and communication technology (ICT). They can also integrate and develop projects in several areas: physical activity, music, health education, and reading, among others.

This paper presents the goals and the foundations of the Program, characterizes the students and describes some of the initiatives that have 
been developed. The data presented are from the period between the second semester of 2007/2008 and the second semester of 2010/2011, focusing particularly in this latter period.

\section{Program context and relevance}

The awareness that the world population is aging rapidly (by underlying social and economic implications) and that many elderly people face serious situations of exclusion and discrimination has been the basis of the increasing concern with their rights of citizenship. The progressive and marked increase of the number of elderly (and very elderly) can become problematic if some attitudes and behaviours are not reconsidered and if derogatory judgments are made of their real skills, which lead us to ignore the valuable contribution that they can bring to the development of societies remain. Their social, political and labour involvement is a way to overcome the adverse effects of aging and lead to successful aging.

There are several concepts that reflect a new concern about aging quality and the need to build new conceptions about aging and the elderly: active aging, productive aging, and successful aging. All of them, despite their conceptual specificity, bring us to the importance of involving older people in meaningful activities, promoting their personal development and having a positive impact on their lives and of those around them.

Following the Second World Assembly on Ageing, held in 2002 in Madrid, governments and institutional representatives committed to ensure full protection and promotion of human rights and fundamental freedoms, recognizing that, as people get older, they should have opportunities for personal fulfilment, to lead a healthy and safe existence and to participate actively in social, economic, cultural and political life (WHO, 2002).

The European Union, also represented in that Assembly, has developed a diverse set of measures seeking to develop community cooperation in the area of aging (European Commission, 2002). A major objective of these measures is to implement policies and practices in favour of active aging. The main practices include lifelong learning, extending the active 
life period, postponing the retirement age, introducing a more gradual retirement system, maintaining an active life after retirement and developing activities that allow them to optimize individual skills and maintain every person in a good condition of health.

The IPL60+ Program follows this path of promoting aging quality, facilitating social participation and lifelong learning in order to enhance the elders' social role.

Lifelong learning is essential to the constant improvement of skills required in a rapidly changing world, in which changes in technology and demographics put their own challenges and opportunities in the labour market. Nevertheless, lifelong learning and learning in advanced age involve more than just preparing people for the labour market. They are also concerned with preparing people of all ages for full citizenship within their families and communities, enabling them to contribute to the development and take responsibility for it. (Leeson, 2009, p. 268).

Developed in an intergenerational context, the Program enhances the skills of the elderly in the Leiria region, promotes their integration into new social contexts and the use of their knowledge to enrich the education of IPL's younger students. As indicated in the Guide of Ideas for Planning and Implementing Intergenerational Projects

... teaching practices and intergenerational learning can contribute to a balance of disparities and to overcome social segregation, promoting greater capacity for understanding and respect between generations, allowing the development of inclusive societies. (Pinto, 2009, p. 6).

It is an initiative that brings together interests and desires of several generations, being a privileged space of interaction and acquaintanceship, which facilitates the development of actions that depend on the mobilization of human and social skills of the various subjects involved, and may assume a more educational or recreational aspect, depending on the intra-and intergenerational dynamics created. 


\section{Institutional framework}

The IPL60+ Program started in the second semester of 2007/2008 and consists of a proactive and innovative project, based on a training model with regional impact, supported by sharing and accumulating knowledge and experience, designed for students with 50 or more years of age. Its mission is to help change the paradigm of aging, in order to promote greater autonomy and social contribution of seniors, by invigorating and promoting formative, educational and socio-cultural activities that engage them in their journey of learning and lifelong development. In fact, as referred by Ribeiro and Paúl (2011, p. 11) "successful", "satisfactory" or "active" aging doesn't depend exclusively on factors such as luck or genetic heritage. It depends on each of us, on individual responsibilities and actions".

In this sense, the Program establishes the following goals:

- To expand the domains of knowledge to seniors, allowing them access to higher education in a perspective of long-term development and education throughout life.

- To develop cultural activities which promote the relationship between generations in a perspective of social and communitarian involvement and inclusion.

- To get adults (with 50 years or over) to commit to a proactive promotion of their general well-being, through active and healthy living, in a perspective of citizenship and social well-being.

- To contribute to the changing of attitudes and ideals relating the aging process, the retirement and the role of "seniors" in contemporary society, aiming for the quality of life for all.

- To contribute to gerontological research, development and innovation.

\section{Organizational structure}

The IPL60+ Program has been part of "IPL's Strategic Plan" since 2008, depends directly on its Presidency and its management is assured by a 
coordinator. For the performance of her duties, the Coordinator has the collaboration of a Scientific-Pedagogical Committee, composed by herself as chair, two teachers appointed by the Chairman of the IPL, five teachers appointed by each of the directors of the IPL schools, and three student representatives, elected annually by their peers.

\section{Access and frequency conditions}

According to the statutes of the Program, senior students can subscribe to up to 5 projects or classes per semester and are obliged to enrol in at least one Curricular Unit of the IPL's graduate courses. However, there can only be up to five senior students per Curricular Unit. Since attendance of the Program does not grant an academic degree, previous academic qualifications of senior applicants do not constitute access criteria.

The Program registration implies the payment of a subscription fee every six months and a fee for each Curricular Unit or project chosen.

Evaluation is optional. If a student decides to be graded, he will have to abide by the Unit's evaluation rules applied to all students. In case of approval, certification will be issued and the unit can be credited if its holder has or comes to acquire a higher education degree.

\section{Formative and socio-cultural offer}

One of the advantages of the IPL60+ lies in the diversity of training areas available to students since they can develop or acquire knowledge in areas such as Social Sciences, Educational Sciences, Health Sciences, Arts and Design, Engineering or Tourism. Specifically, the universe of choice extends to five schools located in Leiria, Caldas da Rainha and Peniche. An offer that allows the achievement of one of the underlying principles of the intervention: the respect for individuality and uniqueness of interests. 
Senior students may attend all Curricular Units of IPL graduation courses, safeguarding the cases in which, because of their specificity, the teachers responsible deliberate that they should not be open to this public. In addition, as can be seen by the following list, senior students have the possibility of attending Curricular Units specifically created for them and of participating in cultural activities. These may be paid or free, depending on the regularity of the activities and the expenses they carry to the IPL.

The activities subject to a fee are:

- Curricular Units of graduate courses

- Trad'Inovation Project (tradition with ICT innovation)

- ICT (beginner and intermediate)

- English (beginner and intermediate)

- Physical Activity

In turn, the free activities are:

- Dance

- Collaboration on radio IPLAY

- Collaboration on newspaper AKADÉMICOS

- English conversation sessions

- Encounter with the books

- Health for all Seminars and Nursing Advisory Cabinet

- Thematic seminars

- Cultural and recreational activities (cultural visits, gatherings, dinners, etc.)

The IPL60+ Program has a strong academic component, the recreational offer is additional and of the initiative of the Program students or graduate students who are undertaking internships or some other type of work in the field of active aging and lifelong learning. In both cases, the activities are always a result of the suggestions and willingness of the senior students, who almost always assume responsibility for the entire process of planning and implementation.

Relating the graduation Curricular Units, seniors show a particular preference for the scientific area of Social Sciences and Humanities, 
History, Psychology and Sociology in particular, as well as foreign languages. However, the interests are very diverse and are related to the respective personal and professional paths.

Students of the Program also show a high interest in the learning of the English language, as well as Information and Communication Technologies. The difficulty in keeping pace with the younger generations' learning rates in these areas led to the creation of specific classes constituted only by seniors. We believe that the difficulty meeting the pace of graduate classes is due, in particular, to the fact that the content and teaching methodologies are structured for an audience who have previous knowledge in the areas concerned. Unlike younger people, most senior students are at a beginner level and need highly customized support and attention to the specificities of their learning process.

In the ICT field, the Trad'Inovation Project stands out. It is a project which aims to promote an approach to traditions and to traditional and popular culture through ICT, accomplished by the development of activities involving senior students (facilitated by a trainer in the area of ICT) and children of the 1stcycle of basic education from some schools in the region. It has as its main objectives: to perpetuate the traditional and popular culture by making popular Portuguese traditions known, living them and recreating them through ICT and innovative situations; to create an intergenerational dynamic of the traditional and popular culture approach by putting several generations in interaction (children, adults and seniors); to share knowledge and experiences of traditional and popular culture from different countries in a perspective of understanding and acceptance of difference and valorisation of local and regional identities and the promotion of values such as fraternity and universality.

As the IPL60+ is made for and by the people, it seeks to encourage and welcome students' proposals (social, cultural or recreational) and has, therefore, conducted several regular or sporadic initiatives that result from their interests and the mobilization of their skills. An example of this is the project "Health for All", promoted by a retired nurse who attends the Program. This project includes seminars that take place every two weeks and are open to the whole IPL community, and also a Nursing Advisory 
Cabinet, devoted exclusively to screening, counselling and redirecting in the field of health education.

In the same vein of personal initiative encouragement, the "Encounter with the Books" project is maintained by another senior student who shares his knowledge and promotes the involvement of his peers in intellectual and socially stimulating activities.

\section{Dance and physical activity project}

The development of physical activity is another strong component of the Program, along with the academic and socio-cultural components. In a partnership between Gerontomotricity teachers, interns from the Intervention for an Active Aging Masters degree, Sports and Well-being graduate students, and the Research Centre for studies in Human Motricity (CIMH), the Pilot Project Dance and Physical Activity for Older Adults was implemented in the academic year of 2010/2011. The aim was to maintain and improve physical condition as well as quality of movement to perform daily life activities, encourage socialization and develop healthy lifestyles in order to promote an active aging. In the 1st semester, there were 43 people enrolled in Dance and 29 in Physical Activity. In the 2ndsemester, 38 people enrolled in Dance and 42 in Physical Activity. This project is based on study / planning, implementation and evaluation of specific training programs for motor skills. Thus, students' functional fitness (body composition, strength, endurance, flexibility, balance and coordination), health (anamnesis, blood pressure), and self-esteem are assessed four times throughout the school year.

Alongside the dance sessions, strength and flexibility training and balance / coordination and stamina, there were occasional activities such as Hiking, Pedy-papers, Latin dance and Intergenerational Physical Activity Sessions.

The results were very positive, showing that training programs are effective and have corresponded to the defined objectives which were assessed using the Senior Fitness Test by Rikli and Jones (2008). There 
have been improvements in strength and flexibility of upper and lower limbs, aerobic endurance, agility and balance (static and dynamic). In relation to body composition, there was a decrease in fat mass, an increase in muscle mass and an improvement in obesity indices. There was also an improvement in self-esteem levels and benefits verified on the health parameters.

The IPL60+ Program intends to continue developing Physical Activity Programs, reasoned and tested, disclosing the results to the students and encouraging the adoption of healthy lifestyles through physical activity.

\section{Characterization of the target}

To illustrate the evolution of the Program, it is important to start by presenting the evolution of student registrations over the semesters. The data used to profile the students refer to the 2nd semester of 2010/2011.

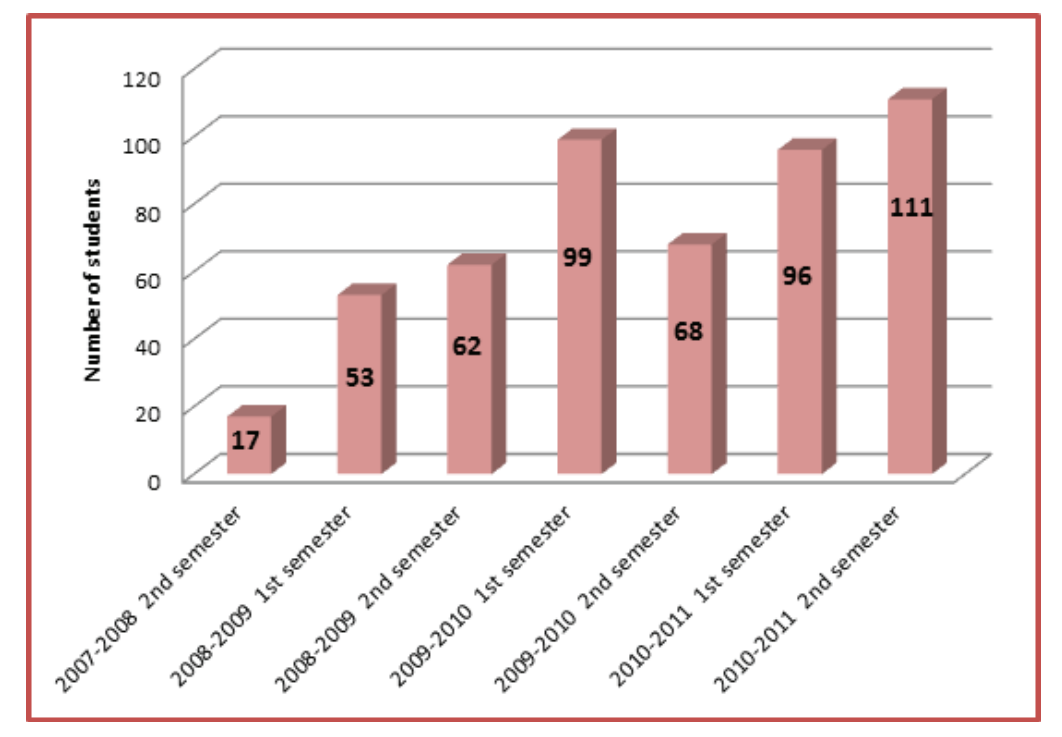

Figure 15: Student distribution by academic semesters

As we can see from the data in figure 15, the number of students enrolled in the Program has grown consistently, with the exception of a decrease seen in the 2nd semester of 2009/2010. In 2010/2011, the growth trend was resumed with a total of 96 students enrolled in the 1st semester and 111 in the 2 nd. 


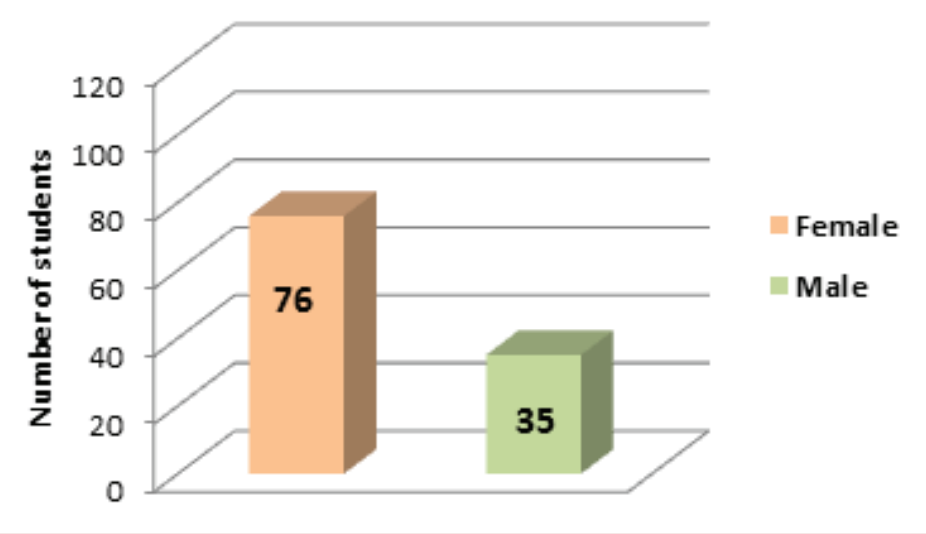

Figure 16: Student distribution by gender - 2nd semester of 2010/2011

As we can see from figure 16, the IPL60+ Program is predominantly sought by females (68.5\%), although there was a slight increase in male students compared to the 1stsemester of the school year in question.

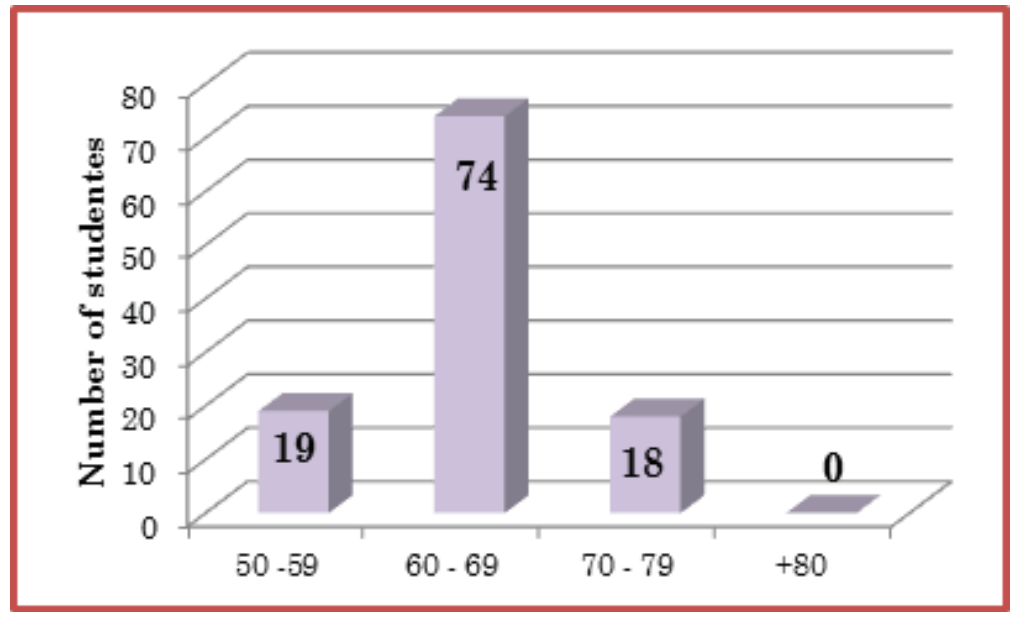

Figure 17: Student Distribution by age - 2nd semester of 2010/2011

Students who attended the Program in the 2ndsemester of 2010/11 were between 50 and 79 years of age, the majority being in the 60-69 age group (67.1\%). 


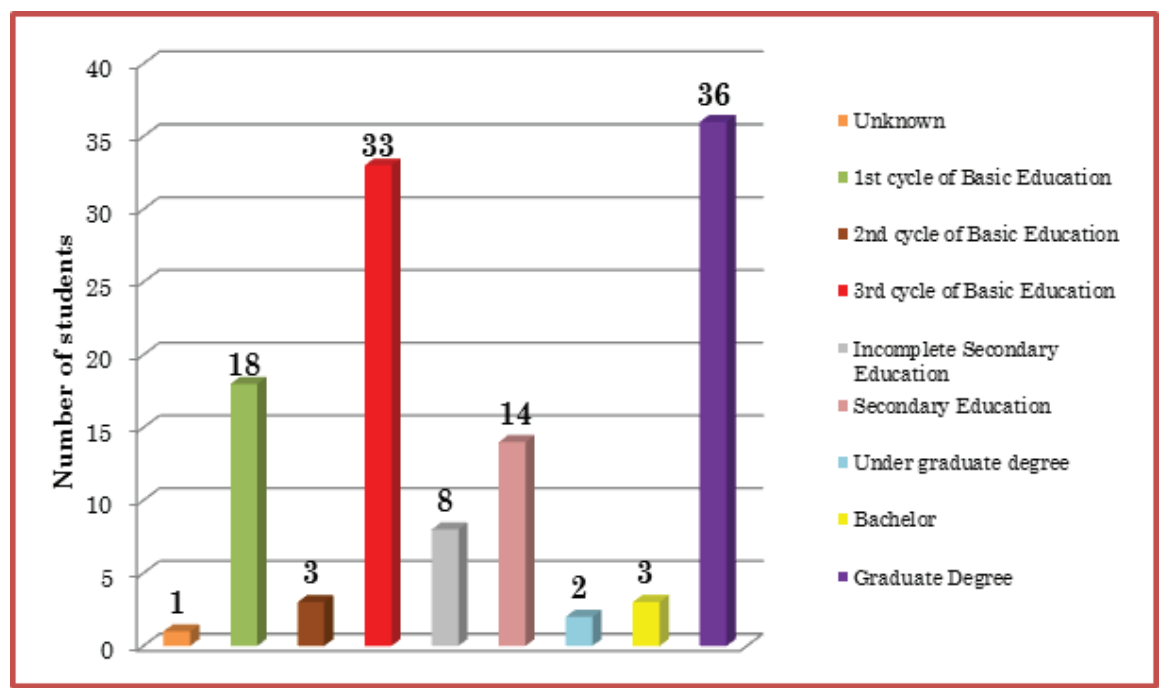

Figure 18: Student distribution by academic qualification - 2nd semester of 2010/2011

The levels of education with greater representation among students enrolled in the 2ndsemester of 2010/2011 are the graduate degree (31.5\%), the 3 rd cycle of basic education (27.9\%), the 1st cycle of basic education $(14,4 \%)$ and secondary education (12.6\%).

Thus, there is a great variety of educational backgrounds, ranging from 1st cycle of basic education to graduate. This diversity lies in the fact that academic qualifications do not constitute Program access requirement, allowing the inclusion of people who didn't have the opportunity to pursue their education.

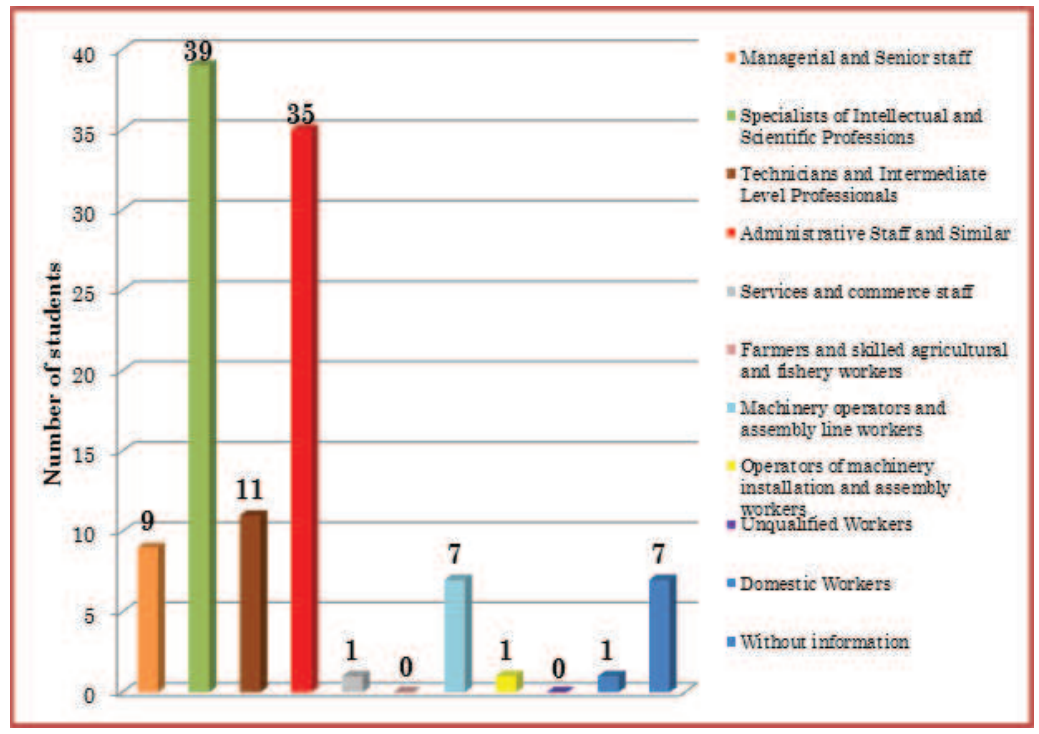

Figure 19: Student distribution by professional categories - 2nd semester of 2010/2011 
With regard to distribution by major occupational categories before retirement (according to the classification used by the Employment and Training Institute), in figure 19 Specialists of Intellectual and Scientific Professions (35.7\%) stand out, among which teachers are at the top of the represented professions $(30=20.8 \%)$. Administrative Staff and Similar come second (31.3\%), followed (with a much lower percentage) by Technicians and Intermediate Level Professionals (9.8\%) and Managerial and Senior Staff (8\%).

It is important to emphasize that the diversity of occupations is such that the categories Skilled Workers of Agriculture and Fisheries and Unqualified Workers are the only ones in which there is no representation.

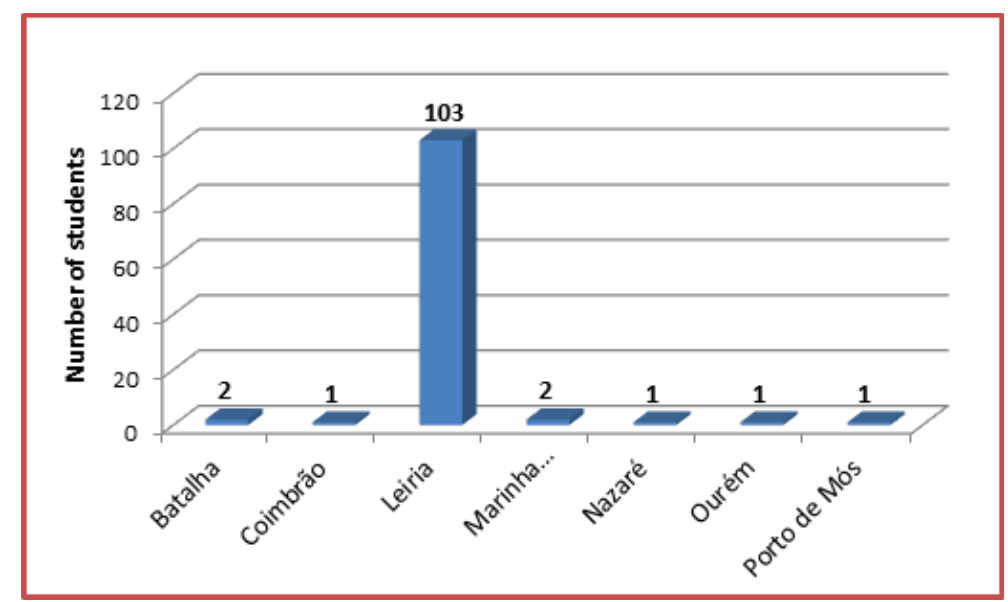

Figure 20: Student distribution by residence - 2nd semester of 2010/2011

Most students enrolled in the 2ndsemester of 2010/2011 (92.8\%) resided in the city of Leiria and the remaining in nearby localities. The place of residence seems to be related to preferences regarding schools attended. Thus, the Curricular Units and activities most frequented occur in schools located in Leiria: the Education and Social Sciences School, Health Sciences School and Technology and Management School.

\section{Evaluation: An undervalued option}

Although senior students may choose to be assessed in the Curricular Units they attend, undergoing a similar process to that of their younger 
peers, only a minority has embarked on a formal evaluation, having, however, completed it successfully.

Since the beginning, the number of students formally evaluated has remained low. Noteworthy is the 1stsemester of 2010/11 in which, so far, the highest participation in curricular evaluation was registered. Even so, in this semester only 7 of the 96 students enrolled were evaluated in 9 Curricular Units. As an example, we present the detailed data of this period.

Table 3: Students Assessed in the 1st semester 2010/2011

\begin{tabular}{llc}
\hline Student ID & Curricular Unit & Rating obtained \\
\hline Student A & Social Intervention in Risk Groups & 15 \\
Student B & History of Portugal & $10^{*}$ \\
Student C & Discourse Analysis & 13 \\
Student C & Lusophone Cultures & 18 \\
Student C & Communication and Oral expression in Chinese I & $13 *$ \\
Student C & Chinese I & $14 *$ \\
Student C & Portuguese Language I & 13 \\
Student D & English & 17 \\
Student E & English & 14 \\
Student F & English & 12 \\
Student G & General Principles of Law & 12 \\
\hline
\end{tabular}

*Rating obtained by final examination, following a regular evaluation failure.

From analysis of this table, one student stands out as having been formally evaluated in five Curricular Units, with an average of 14 out of 20 , despite having failed a regular evaluation in two of them. In a more detailed analysis of the 4 years of the IPL60 + Program, we find individual cases of students who invested heavily in the curricular dimension of the Program, the most emblematic one being the case of a student who within 2 years successfully completed 9 Curricular Units. In the 2ndsemester of 2009/10 alone, she achieved an average of 16 out of 20 in 4 Curricular Units, in this case without any failure.

Regarding the Curricular Units in which there is a higher concentration of senior students undergoing formal evaluation, it varies from one semester to the other. In 2010/11, English and Problems of Society and Contemporary Cultures ( $2^{\text {nd }}$ semester) stand out while in 2009/10 the focus goes to Psychology of Education ( $1^{\text {st }}$ Semester), Developmental 
Psychology and Spanish (2 $2^{\text {nd }}$ Semester) all of them with 3 students successfully evaluated.

\section{Final reflection}

Investment in training and lifelong learning, developing intellectually, physically and socially stimulating activities, helps to address the aging process in a more positive way and to reduce the impact of potential losses. This will help to achieve the goals of Active Aging, which is presented as one of the pillars of this project.

The students who attend IPL60+ Program exhibit the most diverse motivations and interests, requiring constant attention to their specific needs. Allowing the expression of senior students' wills and the participation in the decisions that affect them is another pillar of our intervention, expressed in their increasing involvement in the planning and development of activities, as well as in the organization of the Program itself. The election of student representatives has been shown to be essential due to the mediating role they assume between their peers and the Program coordination.

The relationship between generations is the last pillar to highlight because it allows the enrichment of coexistence, interaction and mutual learning. This is achieved through the participation of senior students in younger students' daily activities, in classes and work groups, but also by the collaboration of graduate and masters students in activities of IPL60+ Program. There has been a growing interest in the Program, evidenced by research work conducted in the context of some Curricular Units and by the implementation of internships.

In conclusion, we want to enhance the important role played by the Program in the daily lives of senior students by promoting their personal enrichment, investing in their physical condition, recognizing their skills and making them aware of new contents and new strategies for understanding social reality and technological developments. From the point of view of younger students, these interactions contribute to their 
global education through the appropriation of values that favour the recognition of a plural and inclusive society, and to the enrichment of their academic training by accessing new knowledge. These exchanges take place in classroom context but also in thematic seminars, meetings and cultural visits.

\section{References}

Comissão das Comunidades Europeias (2002). Resposta da Europa ao Envelhecimento da População Mundial. Promover o Progresso Económico e Social num Mundo em Envelhecimento. Bruxelas. COM (2002) 143 final. Retrieved 22 jan., 2012, from http:// ec.europa.eu/employment_social/social_situation/docs/com2002_0143_pt.pdf.

Leeson, G. (2009). Educação e Aprendizagem ao Longo da Vida. In Fundação Calouste Gulbenkian, O Tempo da Vida: Fórum Gulbenkian da Saúde sobre o Envelhecimento 2008/2009 (pp. 265-286). Cascais: Princípia.

Organisation Mondiale de la Santé (2002). Vieillir en restantactif : Cadre d'orientation. Retrieved 20 Jan., 2012, from http://whqlibdoc.who.int/hq/2002/WHO_NMH_NPH_02.8_ fre.pdf.

Pinto, T. A. (Ed.). (2009). Guia de Ideias para planear e implementar projectos intergeracionais, Projecto Mates - Mainstreaming Intergenerational Solidarity. Associação Vida.

Ribeiro, O., \& Paúl, C. (2011). Manual do envelhecimento activo. Lisboa: Lidel.

Rikli, R., \& Jones, J. (2008). Teste de aptidão física para idosos (S. Bidutte, Trans). São Paulo: Editora Manole. (Original work published in 2001). 


\title{
LIFE HISTORIES AND INTERGENERATIONAL KNOWLEDGE TRANSFERENCE: A CASE STUDY AT THE BANK OF THE NORTHEAST CORPORATE UNIVERSITY
}

\author{
Marcos Marinelli ${ }^{28}$, Luís Alcoforado ${ }^{29}$, \\ Marcos Antônio Martins Lima ${ }^{30}$
}

\begin{abstract}
This communication aims to present, technically and methodologically, the main results of learning experiences as well as life stories within a program in succession at the Bank of the Northeast Corporate University (UC-BNB).It is structured into four parts:in the first, we make a brief approach to the theoretical framework and its relationship with the corporate education system of the organization analyzed; in the second, we outline the methodology used to write this paper, based on a case study, whose data collection techniques were predominantly based on direct observations, document reviews and interviews with the professionals involved in the development and implementation of the learning experiences; in the third, we describe the learning experiences gathered throughout this case study; and finally, in the fourth part, we analyze the results. The results indicate the contribution of skills, recognized by peers and the institution, and attested to by the accomplishment of $93.3 \%$ of program graduates in management positions. Another result refers to a greater contribution of the instructors in the process of training of employees of the Bank of the Northeast of Brazil (BNB), and greater recognition from peers and the institution.
\end{abstract}

Keywords: Learning Experiences; Life Stories; Corporate Education System; Adult Education; Succession Program.

28 Email: marinelli_marcos@hotmail.com; Faculty of Education; Scholarship from CAPES/PDSE.

29 Email: lalcoforado@fpce.uc.pt; University of Coimbra - Faculty of Psychology and Educational Sciences.

${ }^{30}$ Email: marcos.a.lima@terra.com.br; Federal University of Ceará. 